\title{
Experience with misoprostol therapy for NSAID gastropathy in children
}

\author{
Madlen Gazarian, Matitiahu Berkovitch, Gideon Koren, Earl D Silverman, \\ Ronald M Laxer
}

\begin{abstract}
Objective-To determine the effect of misoprostol, a synthetic prostaglandin $E_{1}$ analogue, on the gastrointestinal tract (GIT) symptoms associated with non-steroidal anti-inflammatory drug (NSAID) administration and on the haemoglobin value, in children.

Methods-Retrospective chart review of children attending the paediatric rheumatology clinic at a tertiary referral hospital over a three year period, who were receiving NSAIDs and were prescribed misoprostol for treatment of GIT symptoms or anaemia.

Results-Twenty five children (mean age 12.0 (SD 2.8) (range 7-17) years were prescribed misoprostol (mean dose $308 \cdot 4$ (76.5) $\mu \mathrm{g} / \mathrm{m}^{2} /$ day; $9.8 \quad(2.5) \mu \mathrm{g} / \mathrm{kg} /$ day) while NSAID therapy was continued. Of the $22(88 \%)$ patients with GIT complaints, $18(82 \%)$ had complete resolution of symptoms and two $(9 \%)$ had some improvement. Four patients $(18 \%)$ had a recurrence of symptoms after initial resolution while still receiving misoprostol. Misoprostol therapy was associated with a statistically significant increase in haemoglobin concentration (mean value before misoprostol 115 (18) g/l; after misoprostol 126 (15) g/1 $(p=0 \cdot 02))$. The only adverse effect reported was self limited diarrhoea in one child.

Conclusion-Misoprostol appeared to be effective in the treatment of GIT symptoms in children receiving NSAIDs and to result in significant increase in the haemoglobin concentration. Further prospective studies are needed to evaluate the role of misoprostol therapy for NSAID associated GIT complaints in the paediatric population.
\end{abstract}

(Ann Rheum Dis 1995; 54: 277-280)

Up to $30 \%$ of adult patients taking nonsteroidal anti-inflammatory drugs (NSAIDs) long term experience gastrointestinal side effects, ${ }^{1-3}$ but the incidence of NSAID associated gastropathy in children is not known. However, gastrointestinal symptoms are commonly encountered in children with chronic arthritis treated with NSAIDs and lead to discontinuation or alteration of NSAID therapy, with resultant compromise of arthritis management. ${ }^{4}$ Misoprostol is a synthetic prostaglandin $\mathrm{E}_{1}\left(\mathrm{PGE}_{1}\right)$ analogue with gastric antisecretory and cytoprotective properties. ${ }^{6} 7$ It has been shown in adults to be effective in both the prophylaxis ${ }^{8-11}$ and treatment of NSAID induced gastroduodenal damage, allowing continuation of therapy with NSAIDs while achieving healing of ulcers. ${ }^{10}{ }^{12}$ The major side effect reported has been diarrhoea, which was dose related and often mild and self limiting. ${ }^{13}$ Studies of the efficacy and toxicity of misoprostol in children are few. Recently, there have been two reports suggesting that misoprostol can lead to clinical improvement in children with juvenile rheumatoid arthritis (JRA) who present with NSAID related symptoms, ${ }^{14}{ }^{15}$ but the number of patients studied was small and no firm conclusions could be drawn. We undertook a retrospective study of the children who had been treated with misoprostol through the rheumatology service at The Hospital for Sick Children over the past three years. Our aims were to evaluate the effect of misoprostol on gastrointestinal symptoms and to determine if there were any adverse effects.

\section{Patients and methods}

We undertook a retrospective review of the charts of all children who received treatment with misoprostol through the rheumatology service of The Hospital for Sick Children between February 1990 and February 1993. Information was collected relating to diagnosis, age at commencement of misoprostol therapy, indications for therapy, haemoglobin concentration before treatment, dosage of misoprostol and concomitant medications at the start of therapy. If specific gastroenterological evaluation, such as endoscopy, had been performed at any stage to assess symptoms, these results were retrieved. Outcome measures included subjective physician evaluation of gastrointestinal symptoms at follow up visits, and haemoglobin value within three months of initiation of therapy. Haemoglobin values before and after treatment were analysed statistically using the two tailed Student's $t$ test.

\section{Results}

The charts of 25 children ( 15 females and 10 males) were evaluated. The mean age at the start of misoprostol therapy was $12 \cdot 0$ (SD 2.8) years (range 7-17). The underlying rheumatological conditions included systemic onset JRA 
in four, pauciarticular JRA in seven, polyarticular JRA in six, psoriatic arthritis in three, and spondyloarthropathy in three. There was no definite rheumatological diagnosis in two patients. The mean dose of misoprostol prescribed at the commencement of therapy was $308.4(76.5) \mu \mathrm{g} / \mathrm{m}^{2} /$ day $(9.8(2.5) \mu \mathrm{g} / \mathrm{kg} /$ day) (range $175-520 \mu \mathrm{g} / \mathrm{m}^{2} /$ day (5.6-17.8 $\mu \mathrm{g} / \mathrm{kg} /$ day)), usually given in divided doses twice a day. The maximum prescribed dose at any stage during therapy was $552 \mu \mathrm{g} / \mathrm{m}^{2} /$ day $(800 \mu \mathrm{g} /$ day or $18.87 \mu \mathrm{g} / \mathrm{kg} /$ day $)$. The duration of misoprostol therapy could not be reliably determined from the charts in all cases, but for those available $(n=20)$, the mean duration was 13.6 months (range $1 \cdot 4-37.2$ months). Concomitant therapy included one NSAID in all but one child, who was receiving two. All children had received a minimum of one month of continuous NSAID therapy before starting to take misoprostol. The NSAIDs used and mean (SD) doses (mg/kg/day) were: naproxen $15 \cdot 7(2 \cdot 44)(n=11)$; indomethacin $2 \cdot 19(0.61)(\mathrm{n}=6)$; ibuprofen $23.26(10.62)$ $(\mathrm{n}=2)$; diclofenac $1.94 \quad(0.66) \quad(\mathrm{n}=4)$; tolmetin sodium $24.9(8.53)(n=2)$; piroxicam $0.28(\mathrm{n}=1)$. Other treatment consisted of prednisone $0.21 \quad(0.07) \mathrm{mg} / \mathrm{kg} /$ day $(\mathrm{n}=4)$; pulse intravenous methylprednisolone $(n=2)$; gammaglobulin infusion $(\mathrm{n}=3)$; sulphasalazine $(n=4) ;$ methotrexate $(n=2) ;$ and hydroxychloroquine $(n=1)$.

The main indication for treatment was abdominal pain, which was reported in 22 patients. Seven patients had been treated with sucralfate and one patient had been taking ranitidine and antacids without adequate relief of symptoms, before starting misoprostol. In addition, two patients had nausea, two had vomiting, one had bloating and two had diarrhoea before starting misoprostol therapy. Non-specific gastrointestinal tract symptoms were reported in four patients. Five patients who had anaemia in addition to abdominal pain were treated with oral iron. One patient had no GIT symptoms but had iron deficiency anaemia as the sole indication for treatment with misoprostol.

Eighteen of 22 patients $(82 \%)$ who presented with GIT complaints had complete resolution of symptoms, usually within three months; two patients $(9 \%)$ had some improvement. One patient discontinued treatment after only two days and another discontinued NSAIDs at the same time as starting misoprostol. Four patients $(17 \%)$ had a recurrence of symptoms while receiving misoprostol after there had been initial resolution. However, none of the patients reported an exacerbation of their initial GIT symptoms. One patient experienced a recurrence of abdominal pain after misoprostol was stopped and this was relieved when misoprostol therapy was recommenced.

The mean haemoglobin concentration before commencement of misoprostol therapy was 115 (18) g/l (range 73-136); after treatment it was 126 (15) g/l (range 77-156) $(\mathrm{p}=0.02)$. Six patients were receiving concomitant treatment with an iron sup- plement; the difference in haemoglobin values before and after treatment remained statistically significant $(p=0.01)$ when data from patients who were not receiving the supplementation were analysed separately. The one patient in whom anaemia had been the sole indication for misoprostol had previously been treated with iron supplementation without a satisfactory response. Her haemoglobin was $87 \mathrm{~g} / \mathrm{l}$ before treatment, increasing to $113 \mathrm{~g} / 1$ within three months of starting misoprostol. Iron supplementation was discontinued two months later and her haemoglobin remains satisfactory with continued misoprostol therapy.

With regard to adverse effects, there was only one case of diarrhoea reported; this resolved spontaneously after two weeks while misoprostol therapy was continued unchanged. The dose of misoprostol in this patient was 375 $\mu \mathrm{g} / \mathrm{m}^{2} /$ day. No other adverse effects were reported.

Only two children had upper GIT endoscopy before starting misoprostol. In one the indication was abdominal pain and anaemia; endoscopy showed erosions at the gastrooesophageal junction with oesophagitis confirmed on biopsy. In the other, the indication was abdominal pain alone and endoscopy was normal. The symptoms improved with misoprostol and thus endoscopy was not repeated in these patients.

\section{Discussion}

The present study describes our experience with misoprostol therapy in the largest group of children reported to date. More than $90 \%$ of patients presenting with abdominal pain while receiving NSAIDs had either complete $(82 \%)$ or partial $(9 \%)$ resolution of their symptoms when taking misoprostol, allowing continuation of NSAID therapy in the majority of cases. The study is limited by its retrospective design and the lack of any controls or comparison with placebo. A recent trial in adults reported a placebo response rate as high as $57 \%{ }^{8}$ however, the considerably greater rate of response in our patients, together with the findings that none reported any exacerbation of their abdominal pain and that the majority of patients were able to continue NSAID therapy, suggests a beneficial effect of misoprostol. All children were receiving NSAIDs at dosages within or below the accepted therapeutic ranges and some had failed to derive benefit from other GIT protective agents before starting to take misoprostol. As only two patients underwent endoscopy before commencing misoprostol, the attribution of the GIT symptoms to NSAID therapy in the group overall was purely on clinical grounds. Alternative aetiologies for the abdominal pain experienced by these children may have included the underlying disease process (although systemic onset JRA is the only subtype that is associated with abdominal pain and none of the four patients with this disease was known to have had abdominal pain as a feature of their disease 
before the initiation of NSAID therapy), psychosocial factors, and other concomitant medications such as sulphasalazine, methotrexate, or gammaglobulin infusions, although the numbers receiving these medications were quite small.

Misoprostol is a synthetic $\mathrm{PGE}_{1}$ analogue. Its mechanisms of action include inhibition of gastric acid secretion through a direct action on parietal cells, in addition to mucosal protection through increased mucus and bicarbonate secretion; increased mucosal blood flow; and improved cellular resistance, permeability and regeneration in response to irritants. ${ }^{13}$ Recent information from studies in adults indicates that misoprostol is effective in both the treatment and prophylaxis of gastroduodenal injury induced by NSAIDs. ${ }^{10}{ }^{16}$ With regard to prophylaxis, misoprotol has been shown in comparative trials to be significantly better than placebo and standard antiulcer treatment in the prevention of NSAID induced gastric injury, but misoprostol and $\mathrm{H}_{2}$ blockers provided similar protection against duodenal damage. ${ }^{17}$ Sucralfate has been shown to be inferior to misoprostol ${ }^{9}$ and no better than placebo in the prevention of gastroduodenal damage. ${ }^{18}$ Omeprazole has been shown in volunteer studies to prevent duodenal but not gastric damage, and so provides protection similar to that of ranitidine. ${ }^{19}$ With regard to treatment, cessation of NSAIDs is clearly the best course of action whenever possible, while various agents are useful in achieving ulcer healing. In some patients, however, it may be clinically preferable to continue the treatment with NSAIDs; in this situation, most studies have shown no benefit of $\mathrm{H}_{2}$ antagonists over placebo in healing NSAID induced ulcers and damage during continued administration of NSAIDs, ${ }^{20-22}$ and sucralfate has also been found not to be useful in the healing of gastric erosions and ulcers during continued treatment with NSAIDs. ${ }^{23}{ }^{24}$ While there is a paucity of information regarding the management of NSAID gastropathy in children, our findings are consistent with the results of two recently published studies of NSAID gastropathy in small numbers of children which also suggested that misoprostol is beneficial, at least in terms of symptomatic improvement. ${ }^{1415}$

We found a statistically significant increase in the haemoglobin concentration after misoprostol therapy, even in those patients who were not classified as anaemic at the start of therapy. Minor amounts of GIT bleeding occur in the majority of patients receiving NSAID therapy, and the mucosal protective action of misoprostol may lead to healing of these minor lesions, resulting in an increase in haemoglobin value. Alternatively, relief of GIT symptoms by misoprostol may have resulted in improved compliance with NSAID therapy, leading to better anti-inflammatory effect and thus an increase in the haemoglobin value through the mechanism of improved disease control. A further contribution to the latter mechanism may have been through the proposed direct anti-inflammatory effect of misoprostol. ${ }^{25}$ We could not assess this in the present study, but others have not reported any change in the activity of arthritis with misoprostol therapy. ${ }^{14}$

Diarrhoea is the most frequently reported adverse event in patients treated with misoprostol. It is a dose related phenomenon and its frequency in adults has been reported to be as low as $6 \%$ in those taking $200 \mu \mathrm{g}$ or less daily and as high as $39 \%$ in those taking $800 \mu \mathrm{g}$ daily. ${ }^{13}$ Diarrhoea seems not to be a major problem in children. ${ }^{14}{ }^{15}$ This was confirmed in our study, in which only one patient $(3 \cdot 8 \%)$, receiving a moderate daily dose, experienced this symptom. In this patient it was self limited, resolving spontaneously while misoprostol therapy was continued.

We have demonstrated that misoprostol relieves the gastrointestinal symptoms associated with NSAID use in children. In the adult population, the issue of the routine use of misoprostol for prophylaxis of gastroduodenal pathology in patients receiving NSAIDs is controversial. ${ }^{10}$ This question has not been examined in the paediatric population. Our retrospective study suggests that misoprostol is effective in the treatment of GIT symptoms in children receiving NSAIDs and that it results in significant increase in the haemoglobin value. Future prospective studies should be designed to evaluate the use of misoprostol in children treated with NSAIDs. If the results of such studies are encouraging, the routine use of misoprostol with NSAID therapy should be considered for the paediatric population.

Dr Gazarian is the recipient of the Abe Shore Ontario Juvenile Arthritis Association Fellowship for 1993. Drs Silverman and Laxer are recipients of Associateships from the Arthritis Society of Canada. Dr Berkovitch is a Fellow of the Cooley Foundation, USA, and Dr Koren is a Career Scientist of the Ontario Ministry of Health

1 Roth S H, Bennett R E. Nonsteroidal anti-inflammatory drug gastropathy. Arch Intern Med 1987; 147: 2093-100.

Coles L S, Fries J F, Kraines R G, Roth S H. From experiment to experience: side effects of nonsteroidal experiment to experience: side effects of nonstero

3 Geczy M, Peltier L, Wolbach R. Naproxen tolerability in the elderly: A summary report. F Rheumatol 1987; 14: 348-54.

4 Barron K S, Person D A, Brewer E J. The toxicity of nonsteroidal antiinflammatory drugs in juvenile rheumatoid arthritis. $\mathcal{F}$ Rheumatol 1982; 9: 149-55.

5 Furst D E. Toxicity of antirheumatic medications in children with juvenile arthritis. F Rheumatol 1992; 19(suppl 33): 11-5.

6 Dajani E Z. Perspective on the gastric antisecretory effects of misoprostol in man. Prostaglandins 1987; 33(suppl 10): of misopr

7 Dajani E Z. Mucosal protective activities of misoprostol in man: an overview. In: Bianchi Porro G, Dajani E Z, eds. man: an overview. In: Bianchi Porro G, Dajani E Z, eds. Gastrointestinal cytoprotection by prostaglandins. Focus on

8 Graham D Y, Agrawal N M, Roth S H. Prevention of NSAID-induced gastric ulcer with misoprostol: Multicentre, double-blind, placebo-controlled trial. Lancet 1988; ii: $1277-80$.

9 Agrawal N M, Roth S, Graham D Y, et al. Misoprostol compared with sucralfate in the prevention of nonsteroidal anti-inflammatory drug-induced gastric ulcer. A randomised, controlled trial. Ann Intern Med 1991; 115: 195-200.

10 Ballinger A B, Kumar P J, Scott D L. Misoprostol in the prevention of gastroduodenal damage in rheumatology. Ann Rheum Dis 1992; 51: 1089-93.

11 Scott D L, Bardhan K D, Bjarnason I, Griffin W M, Fenn G C, Shield M J. Misoprostol and NSAID-associated G C, Shield M J. Misoprostol and NSAID-associated 2): 9 .

12 Roth S, Agrawal N, Mahowald M, et al. Misoprostol heals gastroduodenal injury in patients with rheumatoid arthritis receiving aspirin. Arch Intern Med 1989; 149: $775-9$

13 Walt R P. Misoprostol for the treatment of peptic ulcer and antiinflammatory-drug-induced gastroduodenal ulceration. N Engl f Med 1992; 327: 1575-9. 
14 Hermaszewski R, Hayllar J, Woo P. Gastro-duodenal damage due to non-steroidal anti-inflammatory drugs in children. Br f Rheumatol 1993; 32: 69-72.

15 Mulberg A E, Linz C, Bern E, Tucker L, Verhave M, Grand $\mathrm{R}$ J. Identification of non-steroidal antiinflammatory drug-induced gastroduodenal injury in children with drug-induced gastroduodenal injury in children with

16 Fenn G C, Robinson G C Misoprostol-A logical therapeutic approach to gastroduodenal mucosal injury induced by non-steroidal anti-inflammatory drugs? $\mathcal{F}$ Clin Pharm Ther 1991; 16: 385-409.

17 Lanza F L, Aspinall R L, Swabb E A, Davis R E, Rack M $\mathrm{F}$, Rubin A. Double-blind placebo-controlled, endoscopic comparison of the mucosal protective effects of misoprostol versus cimetidine on tolmetin-induced muscosal injury to the stomach and duodenum. Gastroenterology 1988; 95: 289-94.

18 Lanza F L, Graham D Y, Davis R E, Rack M F. Endoscopic comparison of cimetidine and sucralfate for prevention of naproxen-induced acute gastroduodenal injury. Effect of scoring method. Dig Dis Sci 1990; 35: 1494-9.

19 Oddsson E, Gudjonsson H, Thiodleifsson B. Protective effect of omeprazole or ranitidine against naproxen induced damage to the human gastroduodenal mucosa. World Congress of Gastroenterology 1990; FP22.
20 Roth S H, Bennett R E. Mitchell C S, Hartman R J. Cimetidine therapy in non-steroidal anti-inflammatory drug gastropathy. Double-blind long term examination. Arug gastropathy. Double-blind long

21 O'Laughlin J C, Silvoso G K, Ivey K J. Resistance to medical therapy of gastric ulcers in rheumatic disease patients taking aspirin: a double blind study with patients taking aspirin: a double blind study with
cimetidine and follow up. Dig Dis Sci 1982; 27: cimetidine

22 Wallin B A, Frank W O, Fox M J. The effects of cimetidine on the healing of non-steroidal anti-inflammatory drug induced gastroduodenal damage while continuing NSAID therapy. Am f Gastroenterol 1988; 83: 1076.

23 Caldwell J R, Roth S H, Wu W C, ct al. Sucralfate treatment of nonsteroidal anti-inflammatory drug-induced gastrointestinal symptoms and mucosal damage. Am 7 Mod 1987; 83(suppl 3B): 74-82.

24 Shepherd H A, Fine D, Hillier K. Effect of sucralfate and cimetidine on rheumatoid patients with active gastrocimetidine on rheumatoid patients with active gastro-
duodenal lesions who are taking non-steroidal antiinflammatory drugs. Am f Med 1989; 86(suppl 6A): inflam 54 .

25 Shield M J. Misoprostol: new frontiers; benefits beyond the gastrointestinal tract. Scand $\mathcal{F}$ Rheumatol 1992; (suppl 92): $31-52$. 